\title{
"0 cofre dos libros": unha proposta de ensino-aprendizaxe de Literatura Infantil e Xuvenil a través de Twitter
}

\author{
Muriano Rodríguez, M. ${ }^{a}$ Montserrat \\ Universidade da Coruña, Facultade de CC. da Educación
}

\section{RESUMO}

0 presente traballo xira arredor dunha proposta, encadrada na materia "Literatura Infantil e Xuvenil e a súa Didáctica" (optativa de terceiro curso no Grao en Educación Primaria da UDC), que conta, como protagonistas indiscutíbeis, tanto co Moodle da materia como coa rede social Twitter. Trátase dunha dinámica desenvolta nos dous últimos cursos académicos, denominada "0 cofre dos libros", cuxo obxectivo principal é a elaboración dunha proposta de animación á lectura de carácter grupal, a partir dunha obra de LIX, sendo condición indispensábel para o seu desenvolvemento 0 uso da rede social Twitter desde o principio até o final do proceso. A respecto disto, cada grupo crea unha conta en Twitter cuxo nome está inspirado no autor/a escollido/a, ou na súa obra, e na que emprega o hashtag "\#lixdudc" (Literatura Infantil e Xuvenil e a súa Didáctica Universidade da Coruña) cada vez que publica. Así mesmo, coa creación desta conta, o alumnado participante é asesorado pola docente para facer un uso "profesionalizante" de dita rede social e, entre todos, realizamos un proceso de ensino-aprendizaxe en "mancomún", posto que compartimos e comentamos a información entre todos. Finalmente, amósanse os resultados acadados até 0 momento e preséntanse algunhas propostas de futuro do proxecto.

PALABRAS CHAVE: didáctica, literatura infantil e xuvenil, animación á lectura, redes sociais. 


\section{CITA RECOMENDADA:}

Muriano Rodríguez, M. M. (2018). "0 cofre dos libros": unha proposta de ensino-aprendizaxe de Literatura Infantil e Xuvenil a través de Twitter. En E. de la Torre Fernández (ed.) (2018). Contextos universitarios transformadores: retos e ideas innovadoras. II Xornadas de Innovación Docente. Cufie. Universidade da Coruña (páx. 81-100).

DOl capítulo: https://doi.org/10.17979/spudc.9788497496780.081

DOl libro: https://doi.org/10.17979/spudc. 9788497496780

\section{ABSTRACT}

This article aims to present a proposal as part of an elective course: Literature for children and young adults and its didactics, in third year of the Primary Teachers' Training Degree at the University of A Coruña, being its unquestionable ingredients, both the Moodle of the course and the social network Twitter. This teaching and learning dynamics, called "The Treasure Chest of Books", has been implemented during the last two academic years, and its main goal is the preparation of a proposal for reading encouragement in groups. Based on books for children and teenagers, it is an indispensable requirement for its development the use of Twitter from the beginning to the end of the process. Each group of students creates a Twitter account using a name inspired by the author or text chosen by them, and then, they have to use the hashtag "\#lixdudc" (Literatura Infantil e Xuvenil e a súa Didáctica Universidade da Coruña) whenever they publish a tweet. The creation of the Twitter account also allows the teacher of the course to advise her students on the professional usage of this social network. Besides, by working all together, a jointly teaching and learning process will be carried out, creating thus a sharing information environment in the classroom. Finally, the results obtained until now are presented, as well as some proposals for the future.

KEY WORDS: Didactics, literature for children and young adults, reading encouragement, social networks 


\section{INTRODUCIÓN}

A proposta que ofrecemos neste traballo parte, fundamentalmente, da nosa aposta persoal por unha visión absolutamente proactiva do proceso de ensino-aprendizaxe no ámbito universitario. Se ben é certo que, aínda hoxe en día, a disposición espacial das aulas das nosas facultades axuda ben pouco na consideración dun proceso de ensino-aprendizaxe bidireccional e participativo, debemos dicir que é precisamente esa mesma espacialidade de tarima e pupitre -a modo da aula de Fray Luis de León na Universidade de Salamanca- a que tamén reflicte, en certa medida a pasividade que, en numerosas ocasións, adopta o noso alumnado. Nesta orde de cousas, e levando esta reflexión inicial ao tema que nos ocupa, é evidente que estamos ante o risco do que sinalan Gutiérrez, Palacios y Borrego (2010), pois "la posibilidad de considerar las TIC como medios de expresión creativa, de participación democrática queda muy lejos de las percepciones y expectativas de los actuales estudiantes" (p. 291).

Así pois, buscamos subir un chanzo máis, pero subilo en compaña, sen desequilibrios, facendo que o noso alumnado adquira autonomía na súa aprendizaxe, unha autonomía que, ao noso ver, é a que nos leva a querer saber máis sobre determinado tema, pois aquilo ao que chegamos por nós mesmos sempre o valoramos moito máis. Trátase nesta ocasión de fomentar esta autonomía a partir do emprego da rede social Twitter, que non lle resulta allea ao alumnado. Non obstante, as suspicacias sobre as posibilidades pedagóxicas desta e outras redes é, nun principio, moi habitual entre os nosos estudantes. É neste punto onde cómpre reflexionar sobre os conceptos de "nativos dixitais" e "inmigrantes dixitais" (Prensky, 2010). Así pois, e tendo en conta os termos acuñados polo pedagogo estadounidense, a docente situaríase no polo das "inmigrantes dixitais" e os estudantes no dos "nativos dixitais"; mais, se isto é realmente así, por que formulamos entón esas suspicacias dos nosos estudantes cara á empregabilidade das redes sociais como ferramentas pedagóxicas se, en principio, deberían sentirse "coma peixe na auga"? 
Pois porque "educar al joven con superpoderes requiere de la implicación de padres, profesores, la "tribu" en general de la que suele hablarse en educación" (Reig, 2017, p. 1340). Que sucede se nós, os supostos "inmigrantes dixitais" non nos implicamos ou non entramos neste novo modo de entender a educación?

Lo que encontraremos en las aulas, en casa, entonces, serán huérfanos digitales, jóvenes aburridos, desmotivados, practicando la ley del mínimo esfuerzo para superar el trámite de una educación hecha para seres humanos distintos. Estudiarán, sí, dos días antes del examen, pero olvidarán pronto 10 aprendido, que nunca entenderán vinculado a la realidad que los adultos desconocen (p. 1340).

A nosa intención, por tanto, é facer que desapareza esa desconfianza, esa "orfandade", mostrándolles que esa nova realidade está integrada por todos os que formamos o sistema educativo actuando, de maneira conxunta, para enterrar "de una vez por todas la idea, tremendamente arraigada en la mentalidad de todo el staff educativo de que la vida, la vida real, está en otra parte" (Reig, p. 1351).

Por outra banda, na liña desta convivencia coa realidade máis cercana ao noso alumnado, absolutamente familiarizado coas redes sociais, ás que lle dedican gran parte do seu tempo, é na que xurdiu a experiencia que desenvolvemos no presente traballo. Neste sentido, concordamos absolutamente con Mosquera Castro (2015) quen non dubida en recoñecer en Facebook ou Twitter o seu carácter fundamental como:

Medios a través dos que circulan con máis rapidez e intensidade os temas de debate actuais: propician a difusión da información de forma instantánea, alimentan os discursos críticos e achegan aos lectores a múltiplas realidades dun modo máis persoal e próximo que a prensa ou os telexornais (p. 397).

Trátase, pois, de sacarlle partido a estas e outras "bondades" das redes sociais, sen perder a perspectiva pedagóxica que rodea á experiencia desenvolvida no ámbito da didáctica da 
literatura. Así pois, no seguinte apartado, confiamos en transmitir esa función educativa das redes sociais, así como aportar unha visión "profesionalizante" destas que, ao noso ver, deben formar parte do noso día a día coma docentes, ou acaso alguén confiaría nun cirurxián que entrase nun quirófano cunha serra nunha man e unha botella de whisky na outra? E, máis aló do histrionismo que esta imaxe poida provocar, é evidente que sería un feito moi grave e que non habería medio de comunicación que non falase del; mais os mass media pouca ou nula atención lle prestan ao alarmante estatismo das nosas aulas e ás súas consecuencias.

Por outra parte, a proposta presentada vai moito máis aló da pasividade dos chamados "visitantes dixitais" (Hernández, Ramírez Martinell \& Cassany, 2014), isto é, usuarios na busca dun obxectivo ou tarefa concreta, sexa esta enviar un correo, buscar información en Google, etc. Trátase de acercarnos, na medida do posible, e con naturalidade, a ese outro espazo virtual, pois o proceso de ensino-aprendizaxe, nin queda nin debe quedar no estatismo que, en moitas ocasións, xera a aula. Así pois, pensamos que 0 emprego das redes sociais acercaranos tamén a un perfil profesional que integre as seis habilidades dixitais das que fala Rosa (2017) ou, cando menos achegarnos, na medida do posible, a elas: "cultura dixital", "xestión da información", "comunicación dixital, "traballo en rede", "identidade e liderado dixital" e, por suposto, unha "aprendizaxe continua" entendida esta como "capacidad para gestionar el aprendizaje de manera autónoma, conocer y utilizar recursos digitales, mantener y participar en comunidades de aprendizaje" (p. 3769).

\section{DESCRICIÓN DA EXPERIENCIA E RESULTADOS}

Adicaremos este apartado a describir a nosa experiencia, iniciada no curso 2015-2016, na Facultade de CC. da Educación da Universidade da Coruña no marco da materia optativa de $3^{0}$ do Grao en Educación Primaria "Literatura Infantil e Xuvenil e a súa Didáctica": 
Táboa 1. Datos sobre participación. Fonte: elaboración propia

\begin{tabular}{|c|c|c|}
\hline CURS0 & ALUMNADO MATRICULADO & GRUPOS $^{1}$ \\
\hline $2015-2016$ & 26 & 5 \\
\hline $2016-2017$ & 30 & 6 \\
\hline $2017-2018$ & 36 & 8 \\
\hline
\end{tabular}

Así mesmo, pretendemos relatar o noso itinerario en base a algúns principios que consideramos chave. Este é o caso do "Para qué?" xorde esta actividade no marco da nosa materia e, aínda que a cuestión poida parecer simplista, as súas respostas non o son:

- Formar os estudantes como futuros mediadores do hábito lector do seu alumnado de Primaria.

- Achegar os textos e autores máis recoñecidos da LIX.

- Dar a coñecer as editoriais, institucións, revistas, premios... máis senlleiros do sector.

- Recoñecer e poñer en práctica un uso profesionalizante das redes sociais.

- Gozar e compartir a lectura!

Nun primeiro momento, calquera destes obxectivos debería ser de obrigado cumprimento nunha materia como "Literatura infantil e xuvenil e a súa didáctica", mais ese "recoñecer e poñer en práctica un uso profesionalizante das redes sociais" é, probabelmente, un obxectivo inesperado e, damos fe de que así o é no primeiro momento en que se lle presentou 0 proxecto ao noso alumnado. A dificultade radica en facerlle ver que, todos os demais obxectivos poderán acadalos se se "enganchan" a Twitter da maneira en que se lles formula. É chegado este momento cando cómpre falar do "Por qué?". Durante as primeiras sesión expositivas na aula o alumnado responde a un cuestionario elaborado pola docente e denominado "Avalío as miñas competencias. Fágome preguntas" no que responden, entre outros aspectos, sobre os que seguen:

- Teño conta nalgunha rede social (Twitter, Facebook...)? (Indicar cal ou cales).

- Emprégoa para seguir a escritores/as, asociacións, institucións, etc. vencelladas coa literatura castelá ou galega? 
- Sigo algún blogue ou páxina web especializada en literatura infantil e xuvenil?

- Coñezo o nome de, cando menos, dúas editoriais que publiquen literatura infantil e xuvenil?

- Recordo, cando menos, tres nomes de escritores/as de literatura infantil e xuvenil dos considerados "clásicos"?

- Recordo, cando menos, tres nomes de escritores/as de literatura infantil e xuvenil actuais?

Nun primeiro momento, debemos dicir que, efectivamente 0 que 0 lector deste texto intúe é 0 que sucede na maioría dos casos, só a primeira das preguntas obtén un claro "SI" entre a maioría do noso alumnado, eses "nativos dixitais" ou deberiamos dicir máis ben "huérfanos digitales que han aprendido mal a base de ensayo y error" (Dans, 2017, p. 255)? E, si, ao noso alumnado "sóalle" o nome dalgunha editorial que publica LIX (como Anaya, Xerais...) e coñece 0 nome de autores e autoras dos denominados clásicos (Hans Christian Andersen, Lewis Carroll ou Gloria Fuertes, entre eles); mais nin coñecen blogues ou webs adicadas a animación á lectura, ou LIX en xeral², nin tampouco escritores "actuais"3.

Deste xeito, parece que comezar o noso proxecto resulta doado, mais "Cómo?" facerlles ver que acadarán os obxectivos propostos ao comezo do relato desta experiencia. Estas son algunhas das nosas iniciativas que, por suposto, teñen a súa extensión nas redes sociais:

- Compartindo as "nosas" lecturas.

Cada semana un de nós -tanto a docente como 0 alumnado e outros membros da nosa facultade que colaboran con nós altruistamente- trae á aula algunha lectura da súa infancia, ou actual, que o marcase especialmente. Trátase dunha experiencia moi motivadora para todos na que mesmo, en ocasións, a emoción se convirte en protagonista. 


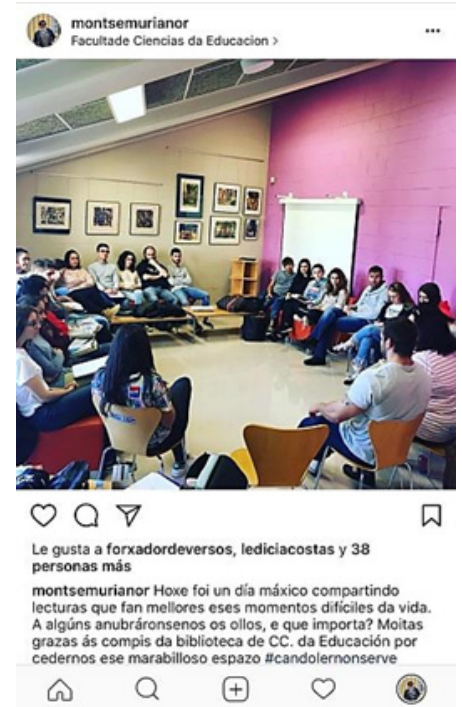

Imaxe 1. Alumnado compartindo lecturas no "Recuncho de lectura" da Biblioteca da Fac. de CC. da Educación. Fonte: Instagram @montsemurianor.

- Invitando á nosa aula a escritores e tamén a docentes con propostas innovadoras de animación á lectura.

\section{โป Biblio de bolsillo ha retwitteado}

Andrea Maceiras@Andrea....17/11/15 v

Xenial a experiencia hoxe en Ciencias da

Educación! Grazas @montsemr! E grazas aos teus alumn@stan riquiñ@s!

\section{Montse MR @montsemr}

Afortunad@s pola presenza na aula de \#lixdudc da nosa escritora da semana @_AndreaMaceiras.

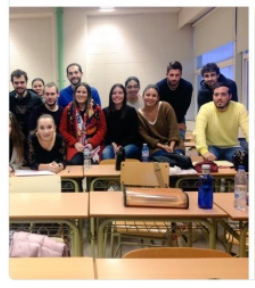

Q $\quad$ \10

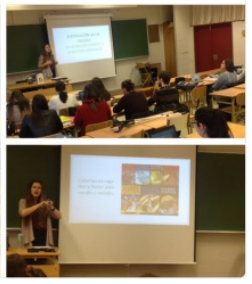

O9 $\quad \square$

Imaxe 2. Visita da escritora Andrea Maceiras. Fonte: @montsemr@_AndreaMaceiras 
- Visitando a Biblioteca Municipal Infantil e Xuvenil do Concello da Coruña. Da man das súas bibliotecarias, adicamos unha sesión a coñecer o funcionamento desta biblioteca, así como as propostas de animación á lectura que se realizan na Rede de Bibliotecas Municipais, facendo especial fincapé nas que van dirixidas ao alumnado de Educación Primaria ${ }^{4}$. Tamén se lle fai ver ao alumnado a importancia de seguir a conta de Twitter das Bibliotecas Municipais -@biblcoruna- pois resulta a forma máis eficaz para estar ao día de presentacións de libros, charlas, concertos ou contacontos, e outras actividades, que nelas se realizan a diario.

- Adicando o noso Moodle a un/a autor/a de LIX cada semana. Baixo o lema "Escritores e frases que fan pensar" adicamos cada semana a un autor/a de LIX clásico ou actual e incorporamos material multimedia relacionado con este ${ }^{5}$.

- Creando as contas de Twitter vencelladas con cada autor e á súa obra.
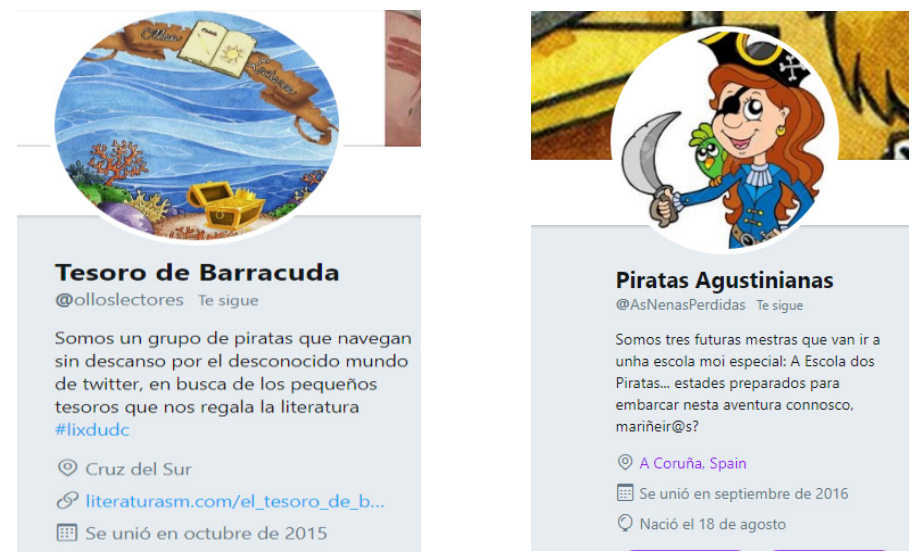

Imaxes 3 e 4. Exemplos de portada dalgunhas das contas. Fonte: @olloslectores @AsNenasPerdidas

- Empregando o hashtag \#lixdudc cada vez que publiquemos.

- Elaborando "0 cofre dos libros", unha proposta de animación á lectura de carácter grupal ${ }^{6}$.

- Presentando a proposta na aula coa participación activa dos compañeiros. Este é 0 final da nosa convivencia na aula, que non nas redes sociais, claro está! 
TI Ledicia Costas ha retwitteado

Tesoro de Barracuda

@olloslectores

¡(a) LibrosCazados nos presentaron a

Escarlatina! @LediciaCostas \#lixdudc
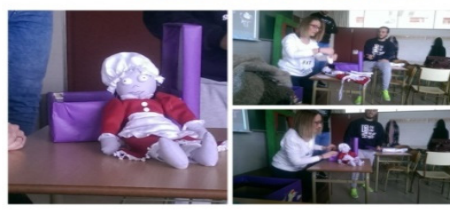

2 Escarlatina

16/12/15 11:59

3 Retweets 6 Me gusta

Q $\uparrow$

Imaxes 5 e 6.0 alumnado difunde as presentacións tamén en Twitter. Fonte: @olloslectores e @perversoslix

Chegados a este punto, quixeramos centrarnos nese "Cómo?", mais dun xeito mais concreto, e continuando con esa visión durativa do proxecto que lle confire o uso do xerundio. Así pois, centrarémonos tamén no que denominamos "Propoñendo retos en 140":

- Adiviñas como forma de crear o interese pola súa proposta no resto dos grupos.

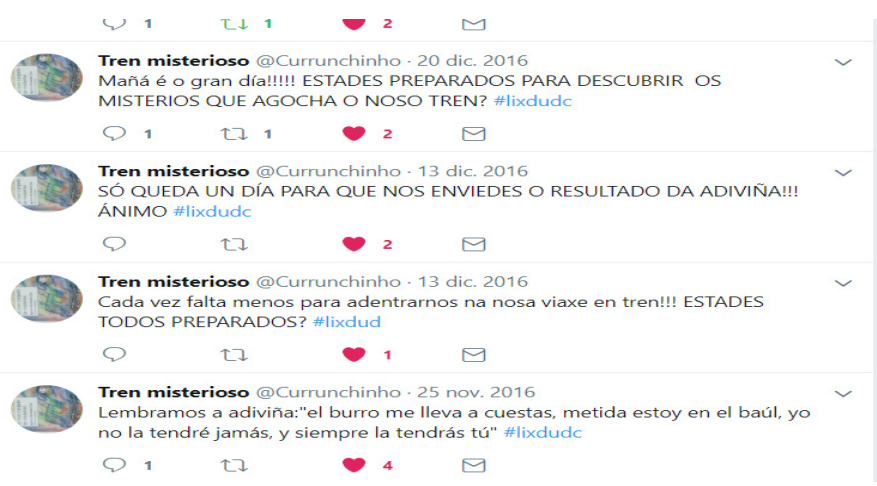

Imaxe 7. Adiviñas en Twitter como recurso para captar a atención cara á proposta de animación sobre Un tren cargado de misterios, de Agustín Fernández Paz. Fonte: @Currunchinho 
- Enquisas que parten das lecturas de aula.

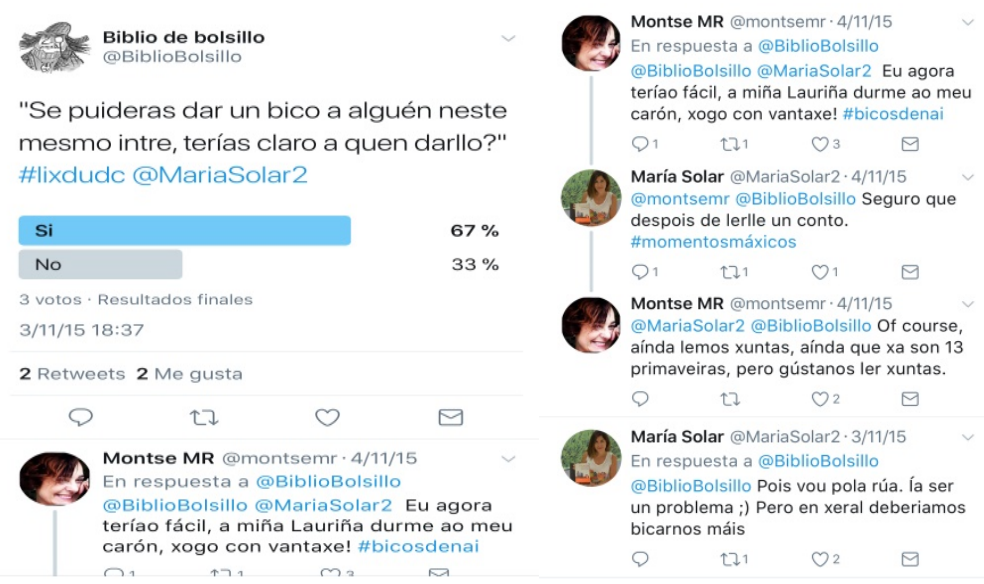

Imaxes 8 e 9 . Enquisa a partir da lectura e comentario na aula d' "A repartidora de bicos", capítulo d' 0 meu pesadelo favorito de María Solar. Fonte: @BiblioBolsillo @montsemr @MariaSolar27

- Recomendación lectoras. Os grupos recoméndanse lecturas entre eles case a diario.
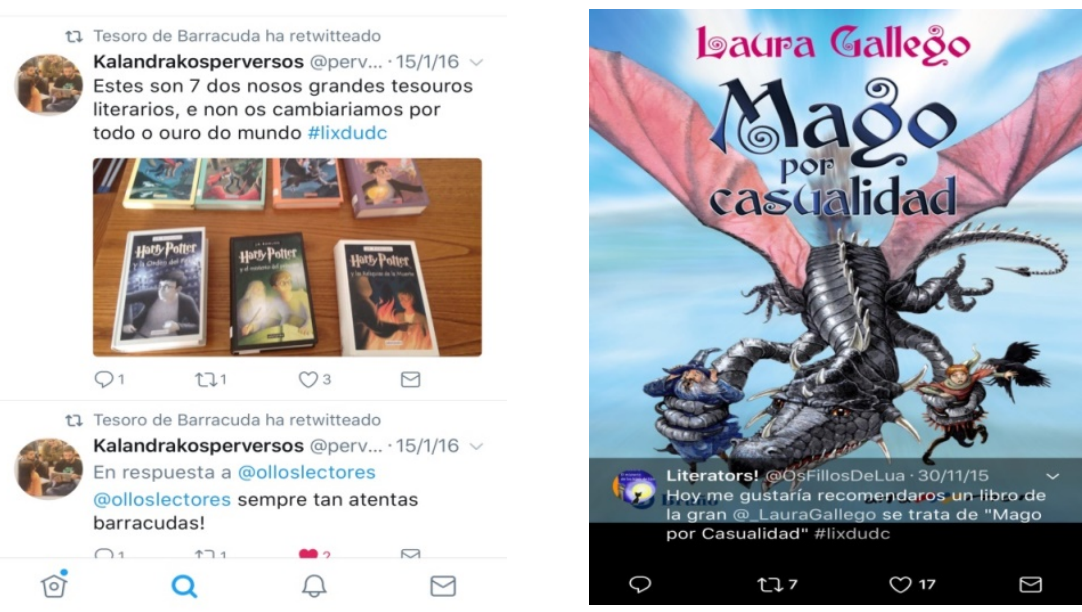

Imaxes 10 e 11. Recomendacións lectoras. Fonte: @perversoslix @0sFillosDeLua 
- Na busca do tesouro. Cunha linguaxe autenticamente pirata os nosos grupos dannos pistas dos tesouros literarios que nos agardan nos seus "cofres de libros".
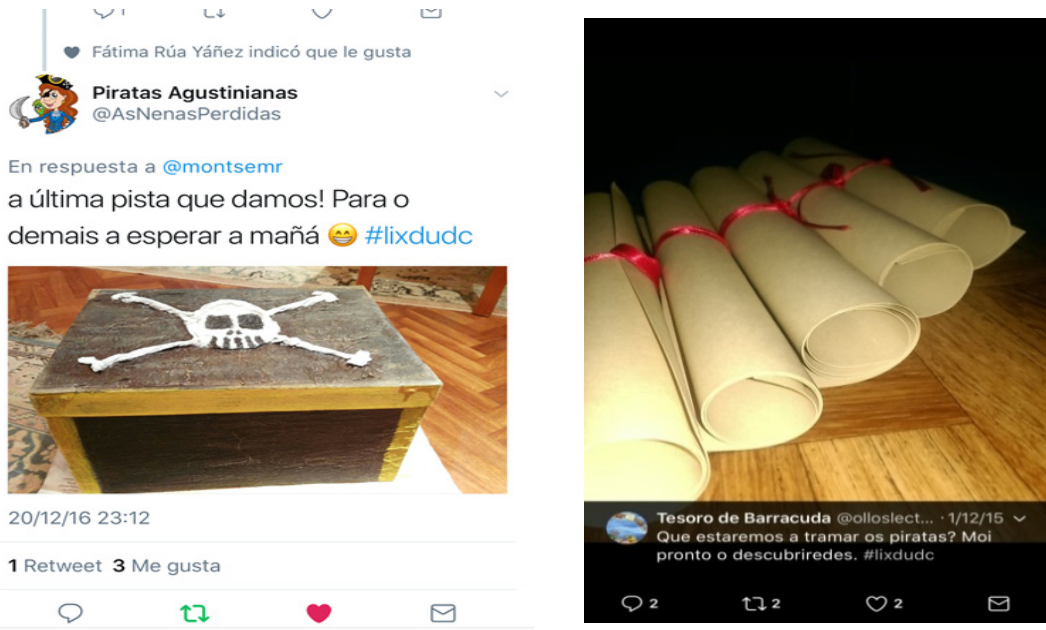

Imaxes 12 e 13. Os nosos piratas do Twitter. Fonte: @AsNenasPerdidas @olloslectores

- Os personaxes tamén chían. Nalgúns grupos é o protagonista do libro sobre o que van facer a proposta de animación quen publica na conta de Twitter. Deixamos claro, pois, que a imaxinación do noso alumnado non ten límites, só os dos 140 caracteres.

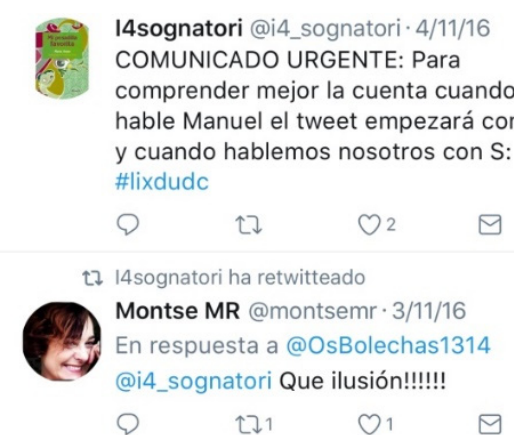

Imaxe 14. Manuel, o protagonista d'0 meu pesadelo favorito ten a palabra no Twitter. Fonte: @i4_sognatori

0 relato da nosa experiencia vai rematando, e que mellor forma de facelo que coa última das accións, que denominamos "Convidándonos a unha viaxe emocionante": 
- Entre eles. A viaxe entre eles é, ao noso entender, a máis satisfactoria; non só polas recomendación lectoras, das que falamos máis arriba (imaxes 10 e 11), senón porque se trata de alumnado procedente de grupos diferentes -A ou B- e que son auténticos descoñecidos antes de comezar a materia, mais, cando esta finaliza, 0 vínculo continúa, e mesmo chega aos grupos futuros.

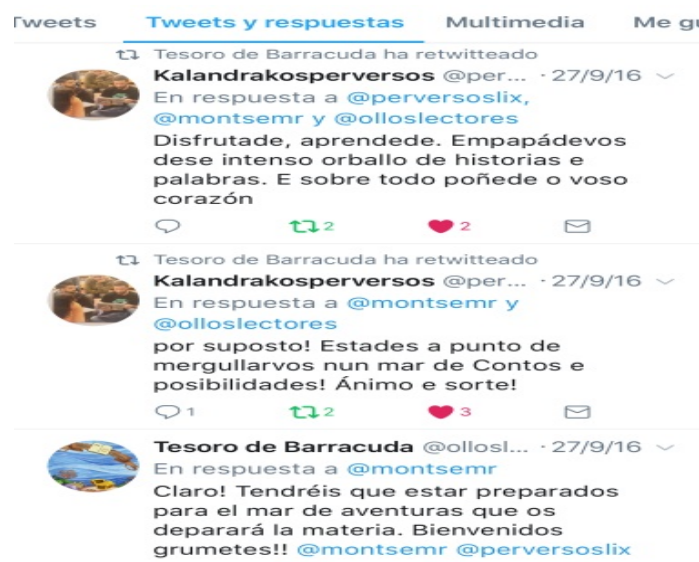

Imaxe 15. Mensaxes de alento para os grupos que inician a viaxe. Fonte: @perversoslix @olloslectores

- Coas súas familias. As familias do noso alumnado son protagonistas en numerosas ocasións cando na actividade "Compartindo lecturas" traen consigo as historias que lles contaban os seus avós ou os seus pais que, posteriormente, compartimos en Twitter.

Biblio de bolsillo @BiblioBolsillo·1/12/15

Ayer entrevistando a mi escritor favorito.

El abuelo Couso

"Memorias de un abuelo"

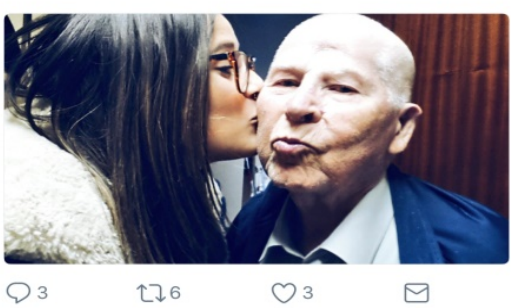

Imaxe 16. Os avós entran en \#lixdudc. Fonte: @BiblioBolsillo 
- Coas nosas autoras.

Son numerosas as ocasións nas que as escritoras e escritores protagonistas da nosa semana de Moodle, ou da proposta de animación á lectura grupal, interactúan con nós e co noso alumnado (véxanse imaxes 2 e 9). Os exemplos que poderíamos aportar son abundantes:

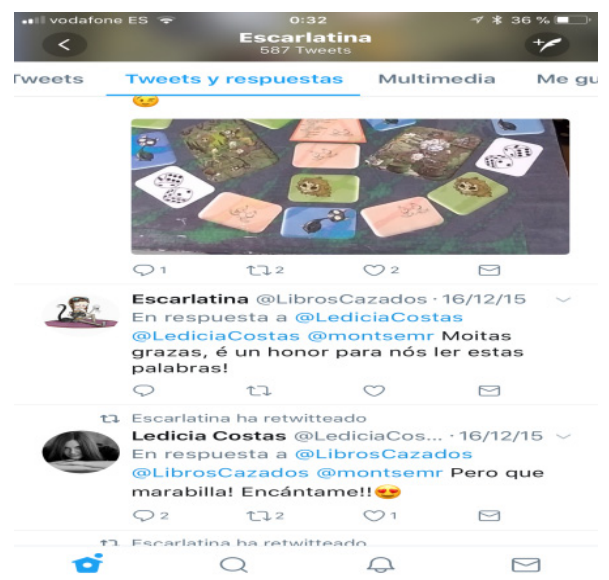

Imaxe 17. Ledicia Costas, autora de Escarlatina, a cociñeira defunta, reponde ao grupo que fixo proposta de animación coa súa obra. Fonte: @LibrosCazados @LediciaCostas

Nalgunhas ocasións, cando a escritora ou escritor protagonista da súa proposta didáctica non dispón de conta en Twitter, o propio alumnado busca outras redes sociais -ou mesmo 0 correo electrónico- para contactar con eles, e sempre as respostas constitúen auténticas xoias literarias. 


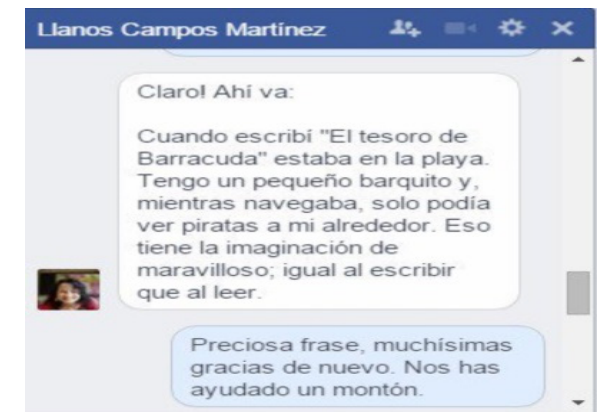

Imaxe 18. Contacto con Llanos Campos, autora de El tesoro de Barracuda, a través de Facebook. Fonte: @olloslectores

- E tamén coa docente. É moi complicado para nós elixir entre as moitísimas conversas que mantivemos -e continuamos a manter- co noso alumnado. Sirva, a modo de conclusión, o seguinte fío:

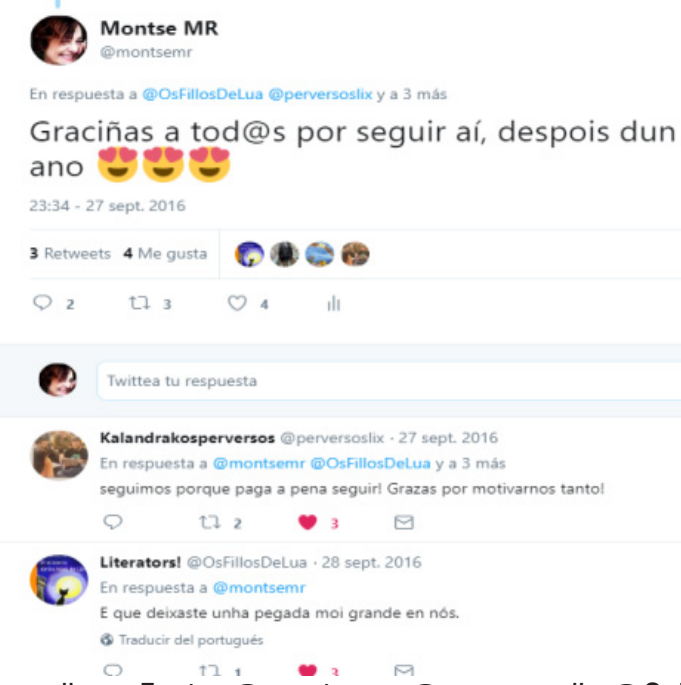

Imaxe 19. Docente orgullosa. Fonte: @montsemr @perversoslix @0sFillosDeLua

\section{PROPOSTAS DE MELLORA E REFLEXIÓNS FINAIS}

Chegados a este punto cómpre sinalar algunhas melloras que comezamos a implementar no presente curso. Así pois, gustaríanos concluír este traballo mostrando algunhas delas, como a creación de contas de Instagram ${ }^{8}$, vinculadas tamén coas de Twitter, nas que, aproveitando a 
importante difusión desta rede visual (Bañuelos Capistrán, 2015), creamos literatura en imaxes, como o proxecto \#lombopoesía ${ }^{9}$, poesía creada cos títulos dos lombos dos libros:

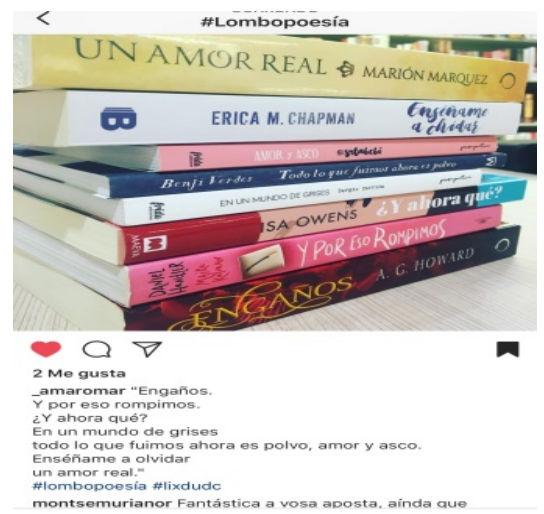

Imaxe 20. Evidencia da acción \#lombopoesía. Fonte:@_amaromar

A acción desenvolveuse na Biblioteca da Facultade de CC. da Educación e o alumnado contou para a súa realización con todo o material bibliográfico desta e, como ferramenta fundamental, cos seus móbiles. Así mesmo, esta dinámica non só os motivou na súa aprendizaxe, chegando a facer moitas máis propostas das que se lles demandaban nun primeiro momento, senón facéndoo consciente dese uso profesionalizante e educativo das redes do que vimos falando desde o principio do noso traballo e tamén comprobando como ese pequeno dispositivo que forma parte das nosas vidas, e sen o que non poderiamos saír da nosas casa, é unha ferramenta educativa de primeira orde.

Por outra banda, quixera facer fincapé no futuro das contas de Twitter dos oito grupos que participan na nosa acción durante 0 curso 2017-2018. Vaia como exemplo a portada dunha desas contas que, sen lugar a dúbidas, promete achegarnos grandes tesouros literarios no seu "cofre": 


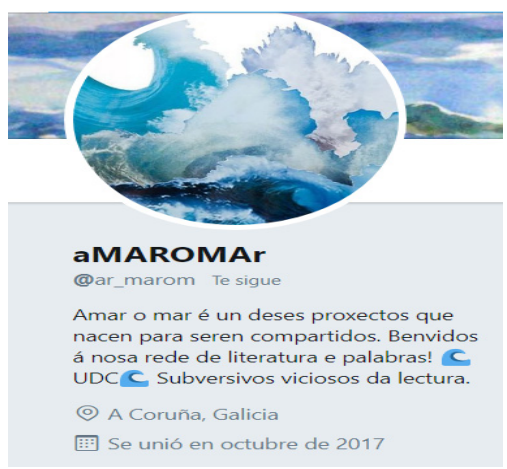

Imaxe 22. Conta de Twitter de @ar_marom

Quixéramos concluír este traballo cunha mirada cara ao futuro chea de optimismo e de confianza nas próximas xeracións de mestras e mestres. E que mellor maneira que reproducir a mensaxe de esperanza que nos deixou en Twitter a escritora Ledicia Costas, Premio Nacional de Literatura Infantil (2015):

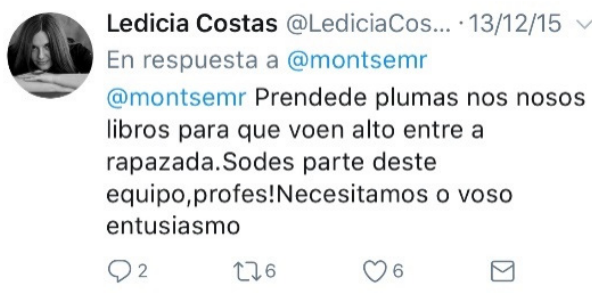

Imaxe 23. Unha porta á esperanza. Fonte: @LediciaCostas

\section{REFERENCIAS}

- Bañuelos Capistrán, J. (2015). Perspectivas epistemológicas para el estudio de la fotografía móvil. En Domínguez Cortina, R. e Solís Hernández E. (Coor $\left.{ }^{\text {as }}\right)$ Memorias Encuentro Nacional de la AMIC pp. 240-270. Recuperado de http://amic2015.uaq.mx/docs/memorias/GI_01_PDF/Gl_01_Perspectivas_epistemolo gicas.pdf

- Dans, E. (2017). Todo ha cambiado. En Lluna Beltrán, S. \& Pedreira García (Wicho), J. (Coors.) Los nativos digitales no existen: cómo educar a tus hijos para un mundo digital. Madrid: Deusto, pp. 195-290 [Versión ebook]. 
- Gutiérrez Martín, A., Palacios Picos, A. \& Torrego Egido, L. (2010). La formación de los futuros maestros y la integración de TIC en la educación: anatomía de un desencuentro. Revista de Educación, 352, pp. 267-293. Recuperado de http://www.revistaeducacion.educacion.es/re352/re352_TIC.pdf.

- Hernández, D., Ramírez-Martinell, A. \& Cassany, D. (2014). Categorizando a los usuarios de sistemas digitales. Revista de Medios y Educación, 44, pp. 113-126.

- Mosquera Castro, E. A didáctica da lingua e da literatura no marco das TIC: novos códigos e novas aproximacións. En Núñez Sabarís, X. González Sánchez, A., Pazos Justo, C. e Dono López, P. (Eds.). Horizontes Científicos y Planificación Académica en la Didáctica de Lenguas y Literaturas. Húmus: Ribeirão, pp. 393-407.

- Katchadourian, N. (s. d.). Sorted Books project

- Recuperado de http://www.ninakatchadourian.com/languagetranslation/sortedbooks.php

- Prensky, M. (2010). Nativos e Inmigrantes Digitales. Madrid: Distribuidora SEK.

- Recuperado $\mathrm{de}$ https://www.marcprensky.com/writing/PrenskyNATIVOS\%20E\%20INMIGRANTES\%20 DIGITALES\%20(SEK).pdf

- Reig, D. (2017). ¿Por qué debemos estar, nativos e inmigrantes en las redes? TIC, TAP, TEP: de náufragos a nativos. En Lluna Beltrán, S. \& Pedreira García (Wicho), J. (Coors.) Los nativos digitales no existen: cómo educar a tus hijos para un mundo digital. Madrid: Deusto, pp. 1154-1351 [Versión ebook].

- Rosa, F. de la (2017). Un nuevo modelo educativo profesional. En Lluna Beltrán, S. \& Pedreira García (Wicho), J. (Coors.) Los nativos digitales no existen: cómo educar a tus hijos para un mundo digital. Madrid: Deusto, pp 3553-3801. [Version ebook].

\footnotetext{
${ }^{1}$ Os grupos están constituídos por un mínimo de tres estudantes e un máximo de 5 .
} 
${ }^{2}$ Un claro exemplo é "Anatarambana. Literatura Infantil”, o blogue da escritora e especialista en LIX Ana Garralón, que obtivo en 2016 o Premio Nacional de Fomento de la Lectura e que, sen lugar a dúbidas, debe ser un referente para calquera mediador na animación á lectura dos máis pequenos. 0 seu enderezo é http://anatarambana.blogspot.com.es/

${ }^{3}$ É 0 caso, por exemplo dos tres últimos galardoados co Premio Nacional de Literatura Infantil: Ledicia Costas, Alejandro Palomas e , no ano 2017, o poeta galego Antonio García Teijeiro.

${ }^{4}$ Agradecemos a todo o persoal da biblioteca, dirixida por Mercedes Cerdeiras Uria, a súa disposición a recibirnos e colaborar connosco desde hai xa varios anos. Así mesmo, non se trata só dunha saída pedagóxica no marco da materia, dado que o vínculo coa biblioteca permanece no noso alumnado desde o momento que a visitan até que, con posterioridade, se incorporan ao seu labor coma docentes e fan uso dela no seu labor de mediadores na lectura dos máis pequenos.

${ }^{5}$ Para a realización desta actividade contamos tamén coa axuda de ferramentas como a pizarra dixital Padlet ou Symbaloo, entre outras, que, en gran medida, axudan a que 0 alumnado se familiarice con estes recursos no seu futuro como mediadores. Así mesmo, mostrámoslles a nosa canle de Youtube onde temos ordenados por cartafois temáticos os materias audiovisuais que soemos empregar no noso día a día coma docentes. Trátase de evitar a improvisación no ámbito educativo porque empregar un buscador é doado, o que non é doado é seleccionar a información que este nos devolve. Pensamos que 0 bo docente debe tamén ser consecuente neste sentido.

${ }^{6}$ Non dispoñemos de espazo suficiente para compartir aspectos máis concretos sobre a proposta de animación "0 cofre dos libros", mais nesta ocasión farémolo de xeito xeral e só no que respecta ao emprego da rede social Twitter como parte importante dela.

${ }^{7}$ Como se observa na evidencia fotográfica, a propia autora do libro, María Solar, participou tamén neste fío de Twitter.

${ }^{8}$ Algunhas das contas creadas para este curso 2017-2018 son: @de_burbullas, @chocoliteratura, @c_colorin, @_amaromar ou @unpoucodepoetas. A todas elas sumamos a creada pola docente para tal fin, @montemurianor, unha conta de carácter profesional e pública na que compartimos literatura tanto co alumnado coma con escritores, ilustradores, editoriais, booktubers... 
90 Sorted Books project foi iniciado en 1993 pola artista conceptual Nina Katchadourian (Katchadourian, s. d.) e a versión difundida nas redes, \#lomopoesía, é unha revisión deste proxecto que está a acadar un grande éxito, quizais precisamente polo seu impacto visual. 